\title{
Incorporation of Decanethiol-Passivated Gold Nanoparticles into Cross-Linked Poly(Dimethylsiloxane) Films
}

\author{
Motohiro Tagaya $^{1}$ and Masaru Nakagawa ${ }^{2}$ \\ ${ }^{1}$ Department of Metallurgy and Ceramics Science, Tokyo Institute of Technology, 2-12-1-S7-6 Ookayama, Meguro-ku, \\ Tokyo 152-8550, Japan \\ ${ }^{2}$ Institute of Multidisciplinary Research for Advanced Materials, Tohoku University, 2-1-1 Katahira, Aoba-ku, Sendai 980-8577, Japan
}

Correspondence should be addressed to Motohiro Tagaya, tagaya.m.aa@m.titech.ac.jp

Received 18 May 2010; Accepted 11 November 2010

Academic Editor: C. R. Bowen

Copyright (C) 2011 M. Tagaya and M. Nakagawa. This is an open access article distributed under the Creative Commons Attribution License, which permits unrestricted use, distribution, and reproduction in any medium, provided the original work is properly cited.

Cross-linking degree of a poly(dimethylsiloxane) (PDMS) film was controlled, and the incorporation of hydrophobic decanethiolpassivated gold $\mathrm{(Au}$ ) nanoparticles into the film was investigated. FT-IR spectra indicated that the hydrosilylation reaction between a vinyl group and a hydrosilyl group occurred with the cross-linking. The swelling degree of the film in toluene changed with a cross-linker concentration, indicating the control of the cross-linking degree of PDMS film. By EDX analysis, the amount of incorporated Au nanoparticles increased with decreasing a cross-linker concentration, indicating the enlarged free volume of the film. The Au nanoparticle-PDMS composite film containing a cross-linker at $6 \mathrm{wt} \%$ showed brown color attributed to plasmon resonance of Au nanoparticles, suggesting the Au nanoparticles in the film at monodispersion state. The UV-visible absorbance of the composite film decreased without spectralshift by swelling with toluene, and the changes were reversible. The aggregation among Au nanoparticles in the composite film after calcination also depended on the cross-linking degree. Thus, the control of cross-linking degree of PDMS film successfully leaded to a simple way of fabricating the Au nanoparticle-PDMS composite film at the mono-dispersion state.

\section{Introduction}

Metal nanoparticles are expected to have enhanced nonlinear optical properties due to plasmon resonance $[1,2]$, and the resonance is important in the development of optical devices $[3,4]$. The production of a monodispersed nanoparitlcematrix system with a specific cluster size would have a great impact on various technological fields such electronics and catalysis because of the electronic structure [5]. It is known that the conduction band present in a bulk metal will be absent in a nanoparticle, and instead, there would be discrete states at the band edge. The formation of metal nanoparticles in a solid support matrix by different techniques such as impregnation, evaporation, traditional melt quenching, ion implantation, ion exchange, and the solgel methods has been investigated $[6,7]$. Development of easy formation process of the nanoparticle-matrix composite at a low temperature is required.
As a nanoparticle support at a mono-dispersion, inorganic porous materials have been unique potential advantages $[8,9]$. The nanoparticles are formed into the support surface by reduction of metal ion in the pore and the sintering. Although the inorganic porous supports are rigid and durable, it is difficult to prepare nonbreakable self-standing composite film. To be applicable for optics or electronics in next generation, the support materials should have the properties of (i) flexibility, (ii) transparency in visible region and (iii) controllable free volume to accommodate metal nanoparticles.

To meet these needs, poly(dimethylsiloxane) (PDMS) is one of typical elastomer materials with the desirable properties such as flexibility, transparency, chemically inert and thermally stability. The PDMS is attractive material for the development of microcontact printing, filtration film, and microfluid [10-15]. We have reported that locally photo-oxidized patterns on a flat PDMS film allowed us to 
transcribe a pattern of Au nanoparticles into a solid substrate [16]. The PDMS is prone to swelling in the presence of alkane and aromatic solvents because of the hydrophobic and nonpolar nature of the surface. The use of the cross-linked PDMS is the key techniques for achievement of efficient and easy incorporation of metal nanoparticles on a material surface. The crosss-linking degree of the silicone network would be a very important parameter to control the free volume to accommodate the metal nanoparticles.

In this study, we demonstrated the control of crosslinking degree of PDMS film by hydrosilylation reaction and the subsequent direct incorporation of hydrophobic $\mathrm{Au}$ nanoparticles into the swelled PDMS film. The incorporated amount and state of the Au nanoparticles in the PDMS film with the cross-linking degree was investigated.

\section{Experiment}

2.1. Preparation of Cross-Linked PDMS Films. A cross-linked PDMS was prepared by the mixture of liquid PDMS (Sylgard 184A, Dow Corning Co. Ltd.) and cross-linker (Sylgard 184B, Dow Corning Co. Ltd.) in 1.5, 2.0, 3.0, 4.0, 6.0, 8.0, and $10.0 \mathrm{wt} \%$ of cross-linker to liquid PDMS. The mixtures were spin-coated (1000 rpm, $20 \mathrm{~s})$ or casted by a weight of $0.15 \mathrm{~g}$ into a support template (inner size: $15 \mathrm{~mm}$ ) on methylsilylmodified $\mathrm{Si}(100)$ substrates, and the films were cured at $65^{\circ} \mathrm{C}$ for $12 \mathrm{~h}$ to respectively, obtain spin-coated thin or casted thick PDMS films. The cross-linked PDMS film containing a cross-linker of $x \mathrm{wt} \%$ was abbreviated as PDMS $x$. The thickness of the spin-coated thin film and thick film were respectively $450 \mathrm{~nm}$ and $1 \mathrm{~mm}$. The cross-linked PDMS films were immersed in toluene for $1 \mathrm{~h}$ and used after removal of nonreactive crudes.

The cross-linking degree is defined as a decrease rate of hydrosilyl groups before and after the curing, and the degree of the thin films was measured by FT-IR spectral changes. The relative characteristic absorbance of stretching vibration in $\mathrm{Si}-\mathrm{H}$ at $2161 \mathrm{~cm}^{-1}$ to $\mathrm{C}-\mathrm{H}$ asymmetric stretching vibration in $-\mathrm{CH}_{-3}$ at $2965 \mathrm{~cm}^{-1}$, which is abbreviated as $\mathrm{A}_{\mathrm{Si}-\mathrm{H}} / \mathrm{A}_{\mathrm{C}-\mathrm{H}}$, was used. The $\mathrm{A}_{\mathrm{Si}-\mathrm{H}} / \mathrm{A}_{\mathrm{C}-\mathrm{H}}$ before cross-linking $\left(\mathrm{R}_{\text {before }}\right)$ and $\mathrm{A}_{\mathrm{Si}-\mathrm{H}} / \mathrm{A}_{\mathrm{C}-\mathrm{H}}$ after cross-linking $\left(\mathrm{R}_{\mathrm{after}}\right)$ were calculated to define the cross-linking degree $\left(\left(\mathrm{R}_{\text {before }}-\mathrm{R}_{\text {after }}\right) /\right.$ $\left.\mathrm{R}_{\text {before }}\right)$ as a decrease degree of Si-H groups with hydrosilylation reaction. The cross-linking degree was obtained by the average of values of three samples. The swelling degree of the thick films was evaluated by weight changes. After the immersion of completely dried PDMS films in toluene for 1 day, the swelling degree of the PDMS films was defined as a weight change by toluene.

2.2. Incorporation of Hydrophobic Gold Nanoparticles into the Cross-Linked PDMS Films. Decanethiol-(DT-)-passivated gold $(\mathrm{Au})$ nanoparticles having an average metallic core diameter of $2.2 \mathrm{~nm}$ (Tanaka Kikinzoku Group Co., Ltd) were used. The thick cross-linked PDMS films were used for the incorporation of the hydrophobic Au nanoparticles, and the films were immersed in toluene solution containing $\mathrm{Au}$ nanoparticles at the concentration of $5 \mathrm{wt} \%$ for $270 \mathrm{~min}$.
After the immersion, the films were immersed in toluene for $30 \mathrm{~min}$ and completely dried by nitrogen blow. The incorporation amount of the Au nanoparticles was estimated by relative weight ratio of Au to Si element by using a Hitachi S-3000N SEM equipped with EDX mapping function, and the peak ratio of attributed to $\mathrm{M}$ shell in $\mathrm{Au}$ to $\mathrm{L}$ shell in Si spectrum on the cross-section was calculated. The Au nanoparticle-PDMS composite films were calcinated at $550^{\circ} \mathrm{C}$ for $4 \mathrm{~h}$. UV-visible absorbance of the Au nanoparticlePDMS composite films, and a toluene solution containing Au nanoparticles of $2.5 \times 10^{-3}$ wt $\%$ was measured by UVVisible absorption spectrophotometer (Shimazu UV-3100). The absorbance of composite PDMS film containing the cross-linker concentration at $6 \mathrm{wt} \%$ before and after swelling in toluene for $30 \mathrm{~min}$ were also measured.

\section{Results and Discussion}

3.1. Preparation of Cross-Linked PDMS Films. Figure 1(a) shows FT-IR spectrum of PDMS film before the thermal curing. The absorbance lspectrum shows the bands of $\mathrm{Si}-\mathrm{C}$ stretching vibration at $795-800 \mathrm{~cm}^{-1}, \mathrm{Si}-\mathrm{O}$ stretching vibration in $\mathrm{Si}-\mathrm{OH}$ at 850 and $870 \mathrm{~cm}^{-1}, \mathrm{Si}-\mathrm{H}$ rocking vibration at $912 \mathrm{~cm}^{-1}$, Si-O-Si asymmetric stretching vibration at $1025-$ $1080 \mathrm{~cm}^{-1}$, C-H rocking vibration in $-\mathrm{CH}_{3}$ at $1260 \mathrm{~cm}^{-1}$, $\mathrm{Si}-\mathrm{H}$ stretching vibration at $2161 \mathrm{~cm}^{-1}$, and asymmetric stretching vibration in $-\mathrm{CH}_{3}$ at $2965 \mathrm{~cm}^{-1}$. These bands are attributed to the liquid PDMS contains siloxane base oligomers with plural vinyl group $\left(\mathrm{CH}_{2}=\mathrm{CH}-\right)$ and crosslinker contains siloxane base polymers with hydrosilyl $(\mathrm{Si}-\mathrm{H})$ groups.

Figure 1(b) shows FT-IR spectra of the PDMS films containing $10 \mathrm{wt} \%$ of cross-linker to liquid PDMS before and after the curing $\left(65^{\circ} \mathrm{C}\right.$ for $\left.12 \mathrm{~h}\right)$. The characteristic bands of $\mathrm{Si}-\mathrm{H}$ stretching vibration at $2161 \mathrm{~cm}^{-1}$ and asymmetric $-\mathrm{CH}_{3}$ stretching vibration at $2965 \mathrm{~cm}^{-1}$ in $\mathrm{Si}-\mathrm{CH}_{3}$ were clearly observed as compared with the bands before the curing. These bands show side chains of PDMS bone structure. The thermal cure caused a noticeable decrease in the absorbance attributed to $\mathrm{Si}-\mathrm{H}$ group. The spectral decrease indicated that a hydrosilyl group reacted with a vinyl group to form a $-\mathrm{Si}-\mathrm{CH}_{2}-\mathrm{CH}_{2}-$ linkage. It has been reported that a platinum-type catalyst in the regent carried out a hydrosilylation reaction to form the cross-link of Si- $\mathrm{CH}_{2}-\mathrm{CH}_{2}-$ linkage $[17,18]$. By the thermal curing, the cross-linking with a $-\mathrm{Si}-\mathrm{CH}_{2}-\mathrm{CH}_{2}-$ linkage occurred.

Figure $1(\mathrm{c})$ shows cross-linking degree $\left(\left(\mathrm{R}_{\text {before }}-\mathrm{R}_{\mathrm{after}}\right) /\right.$ $\left.\mathrm{R}_{\text {before}}\right)$ of the PDMS films as a function of a cross-linker concentration to liquid PDMS. The cross-linking degree increased with the added amount of cross-linker. The degrees of cross-linker concentration at $1.5 \mathrm{wt} \%$ and $10 \mathrm{wt} \%$ were 0.1 and 0.6 . These results indicated that the free volume decreased with the $-\mathrm{Si}-\mathrm{CH}_{2}-\mathrm{CH}_{2}-$ linkage with increasing the cross-linker concentration.

Figure 2 shows relationship between cross-linker concentration to liquid PDMS and swelling degree by toluene. The swelling degree of PDMS2.0 was $600 \%$, and the value was much larger than that of PDMS10.0 (200\%). The incorporated amount of toluene in the PDMS film at the 


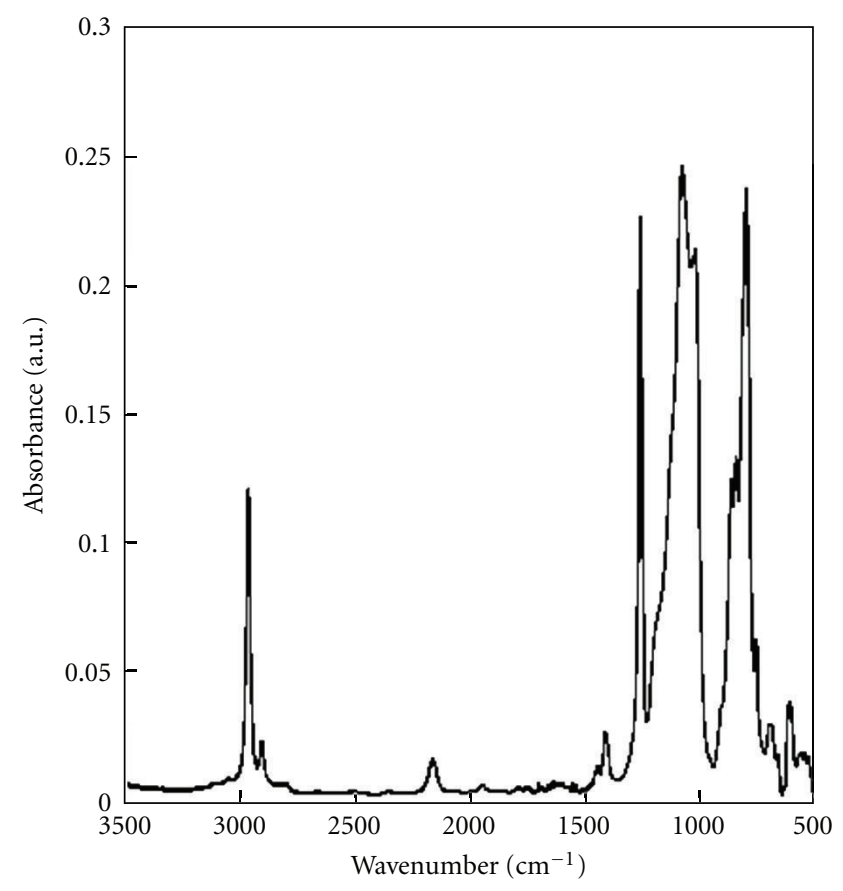

(a)

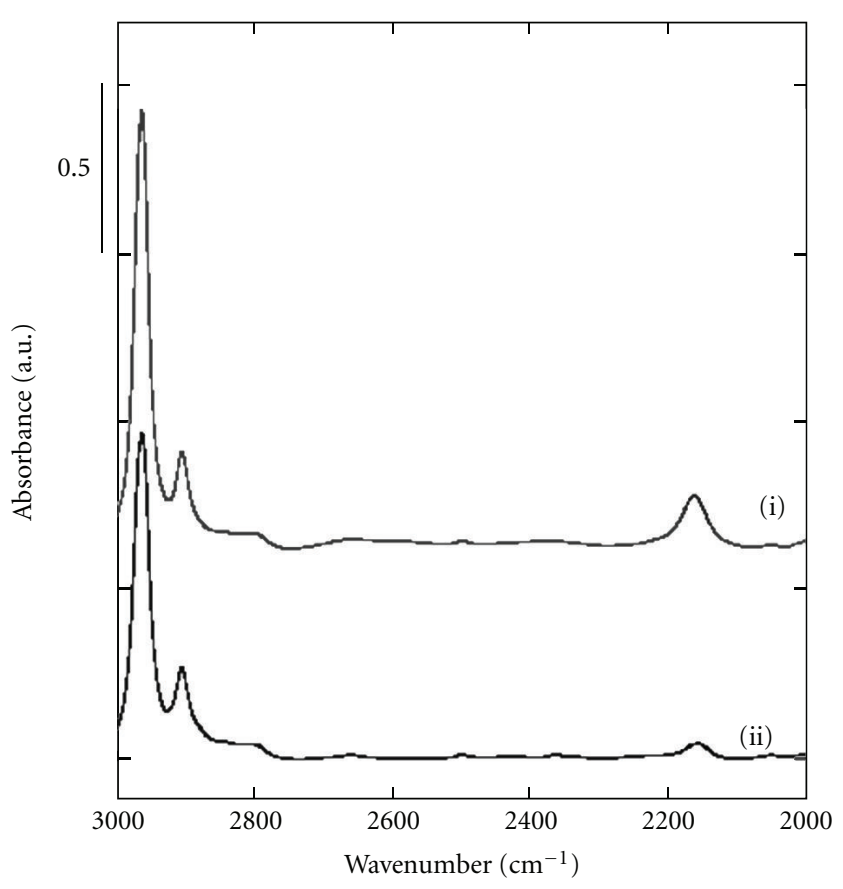

(b)

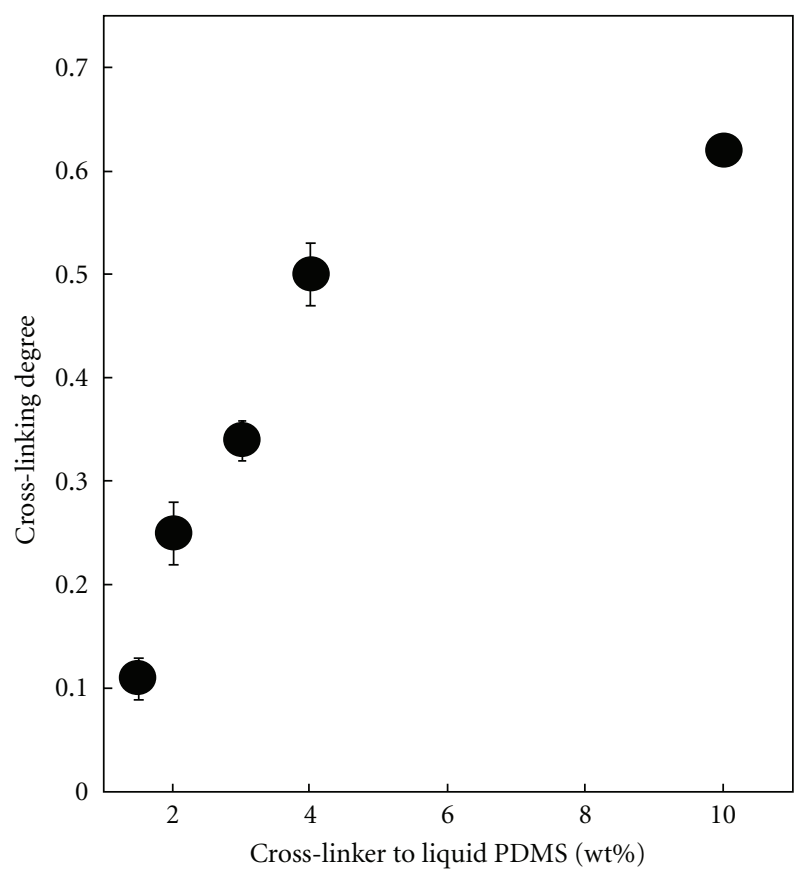

(c)

FIgURE 1: FT-IR spectra of (a) PDMS film before cross-linking and (b) PDMS films (i) before and (ii) after the heat at $65^{\circ} \mathrm{C}$ for $12 \mathrm{~h}$. (c): cross-linking degree of the PDMS films as a function of a cross-liner concentration to liquid PDMS. 


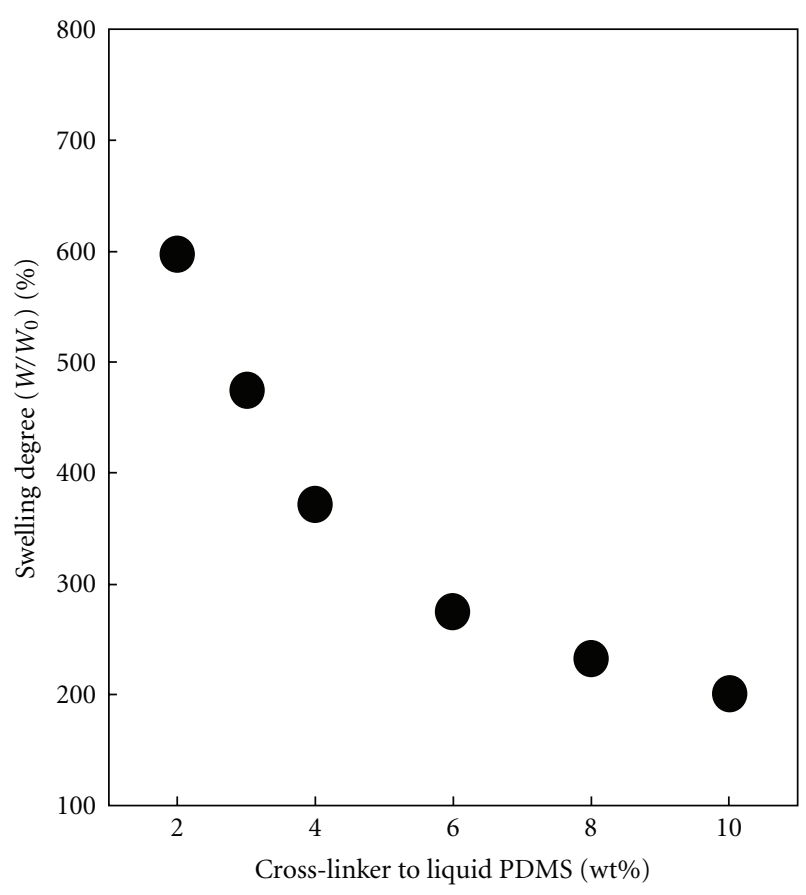

FIgURE 2: Relationship between the cross-linker concentration to liquid PDMS and swelling degree by toluene.

equilibrium swelling state increased with decreasing the cross-linking degree, indicating the formation of free volume constructed by PDMS polymer network.

3.2. Incorporation of $A u$ Nanoparticles into the Cross-Linked PDMS Films. Figure 3 shows (a) UV-visible absorption spectra and (b) photographs of the composite films containing (i) 2, (ii) 4, (iii) 6, (iv) 8, and (v) $10 \mathrm{wt} \%$ of a cross-linker to PDMS. The hydrophobic Au nanoparticles were successfully incorporated into the PDMS films. The incorporated Au nanoparticles adhered on the PDMS film firmly enough not to be flushed out by sonication in toluene, using standard ultrasound equipment. The PDMS4.0 showed a clear plasmon band at around $500 \mathrm{~nm}$, and spectral shape was almost similar to the solution state. Thus, the $\mathrm{Au}$ nanoparitlces would be mono-dispersed in the PDMS film. The absorbance increased with decreasing the cross-linker concentration. The PDMS2.0 showed a spectral shift to longer region, indicating the aggregation of Au nanoparticles in the polymer network. The composite films containing a cross-linker concentration less than $4 \mathrm{wt} \%$ is dark black color as shown in Figure 3(b). Therefore, the Au nanoparticlePDMS composite was successfully fabricated, and the state of incorporated $\mathrm{Au}$ nanoparticles was controlled by the crosslinker concentration.

It has been reported that the hydrophobic Au nanoparitcles was incorporated into silica gel in hexane or toluene for catalyst application. The driving force of incorporation was dipole-dipole interaction between the silanol groups of silica gel and the alkylthiol groups of hydrophobic Au nanoparitcles [19]. The siloxane skeletons of PDMS surface have polar properties, and polar molecules are likely to be captured on the PDMS surface by electrostatic interaction. In this study, the surrounding thiol molecules of the $\mathrm{Au}$ nanoparticles have a permanent dipole moment, and the dipole interaction would anchor the Au nanoparticles on the PDMS surface in low dielectric constant toluene.

Figure 4 shows UV-visible absorption spectra and photographs of the Au nanoparticle-PDMS6.0 composite film (a) before and (b) after swelling. The dashed line shows that UV-visible absorption spectrum of toluene solution containing $\mathrm{Au}$ nanoparticles of $2.5 \times 10^{-3} \mathrm{wt} \%$. The spectrum of composite film before swelling showed a broad absorption due to plasmon resonance band at around $515 \mathrm{~nm}$ superimposed on that of transitions from $5 \mathrm{~d}$ to $6 \mathrm{sp}$ bands [20]. The spectrum is similar to that of the Au nanoparticle solution, suggesting that Au nanoparticles are mono-dispersed in the PDMS film. The absorbance decreased by ca. 50\% without spectralshift by the swelling, and the spectral change was reversible with swelling/shrinkage. The absorbance due to plasmon resonance band found to respond to toluene.

Figure 5 shows change of weight ratio of $\mathrm{Au}$ to $\mathrm{Si}$ element in the composite film as a function of a crosslinker concentration to liquid PDMS. The EDX mappings images of $\mathrm{Au}$ element in the composite films showed the uniform incorporation (data not shown). The weight ratio of the Au to Si in the cross-section decreased with increasing cross-linker concentration. The incorporation amount of Au nanoparticles was successfully controlled by the cross-linking degree.

Figure 6 shows diffuse reflectance UV-visible absorption spectra of the composite films containing (a) 2-10 wt $\%$ of a cross-linker to liquid PDMS after the calcination. The composite film was changed to a solid state by the calcination, indicating new formation of siloxane bonds with decomposition of methyl groups in methylsilyl groups. The PDMS2.0 and PDMS4.0 showed the absorbance at longer region, indicating the aggregation of Au nanoparticles by the calcination. On the other hand, the absorption spectra of cross-linker concentration more than $6 \mathrm{wt} \%$ clearly showed the plasmon resonance band at $530 \mathrm{~nm}$, indicating that the mono-dispersed $\mathrm{Au}$ nanoparitlces remains. The crosslinking in the polymer network would suppress the aggregation among Au nanoparticles against microenvironment changes by the calcination.

\section{Conclusion}

We demonstrated that the cross-linking degree of PDMS film was controlled by a cross-linker concentration. The hydrophobic $\mathrm{Au}$ nanoparticles were efficiently and easily incorporated into the PDMS film and were strongly adhered on the PDMS surface. The incorporated amount and state of the Au nanoparticles in the PDMS film were controlled by the cross-linking degree. The Aucomposite film containing $6 \mathrm{wt} \%$ of cross-linker showed the plasmon resonance of $\mathrm{Au}$ nanoparticles, suggesting the mono-dispersion of $\mathrm{Au}$ nanoparticles in the film. The aggregation state of $\mathrm{Au}$ nanoparticles in the composite film before and after calcination clearly depended on the cross-linking degree. To our 


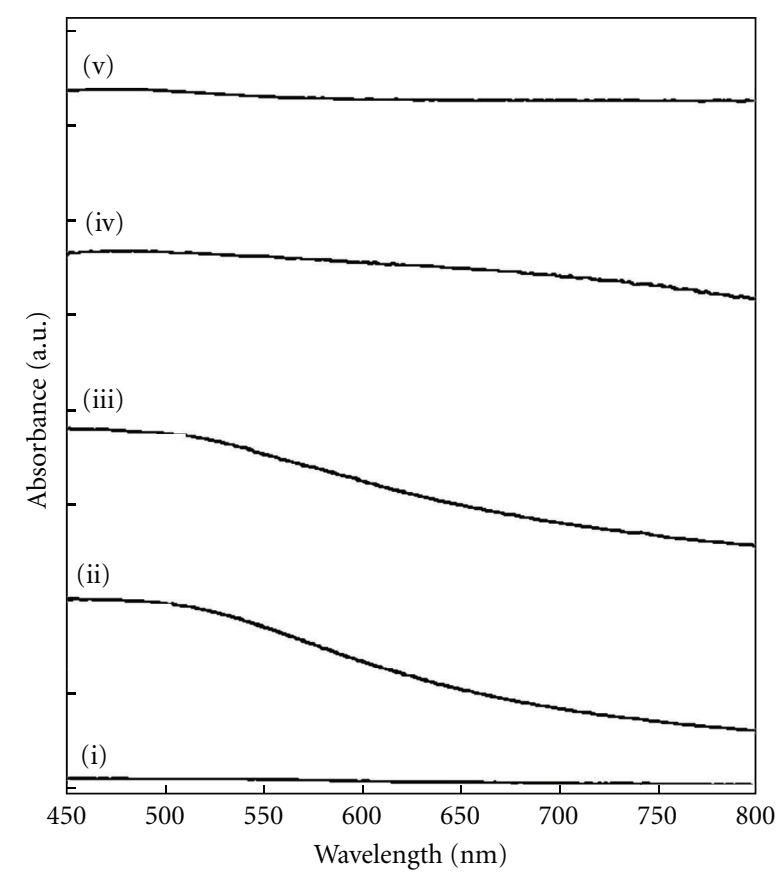

(a)

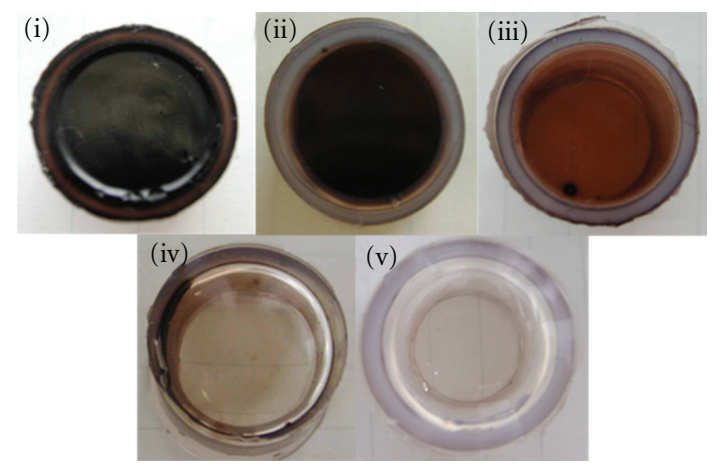

(b)

Figure 3: (a) UV-visible absorption spectra and (b) photographs of the composite films containing (i) 2, (ii) 4, (iii) 6, (iv) 8 and (v) 10 wt $\%$ of a cross-linker to liquid PDMS.

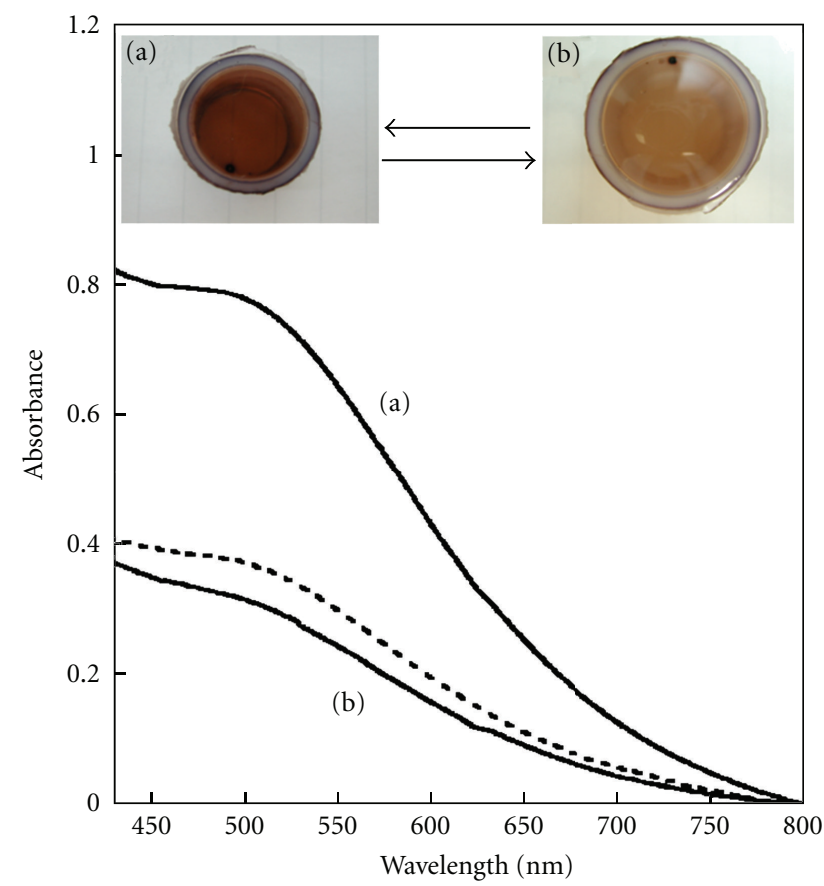

FIGURE 4: UV-Visible absorption spectra and photographs of the Au nanoparticle-PDMS6.0 composite film (a) before and (b) after swelling. The dashed line shows UV-Visible absorption spectrum of toluene solution containing Au nanoparticles at the concentration of $2.5 \times$ $10^{-3} \mathrm{wt} \%$. 


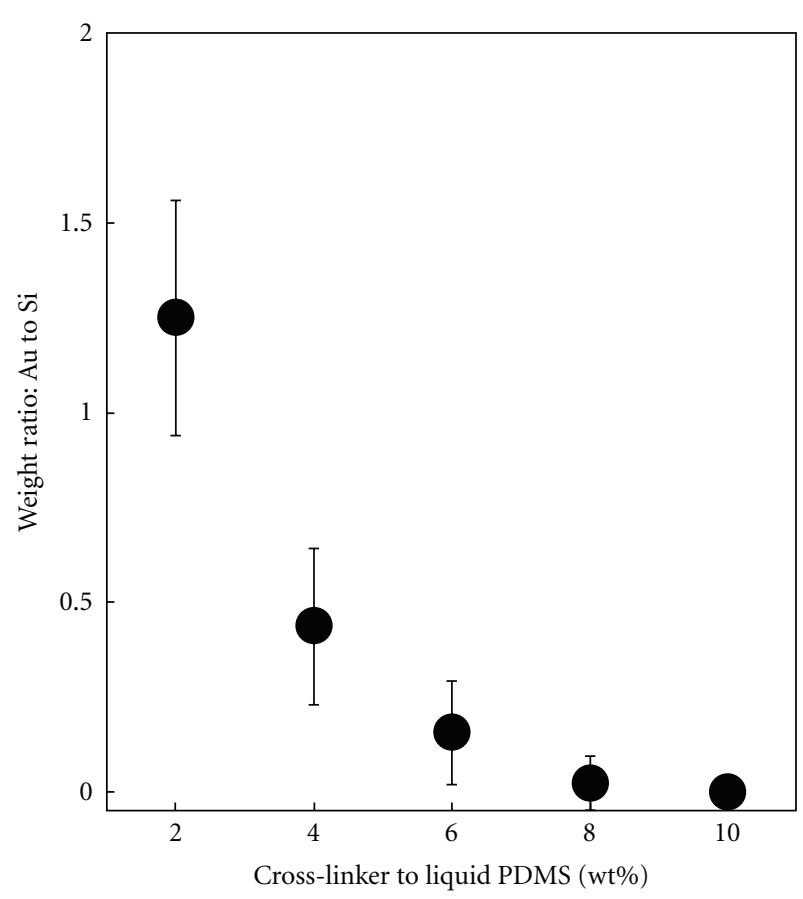

Figure 5: Change of the weight ratio of $\mathrm{Au}$ to Si element in the composite films as a function of the cross-linker concentration.

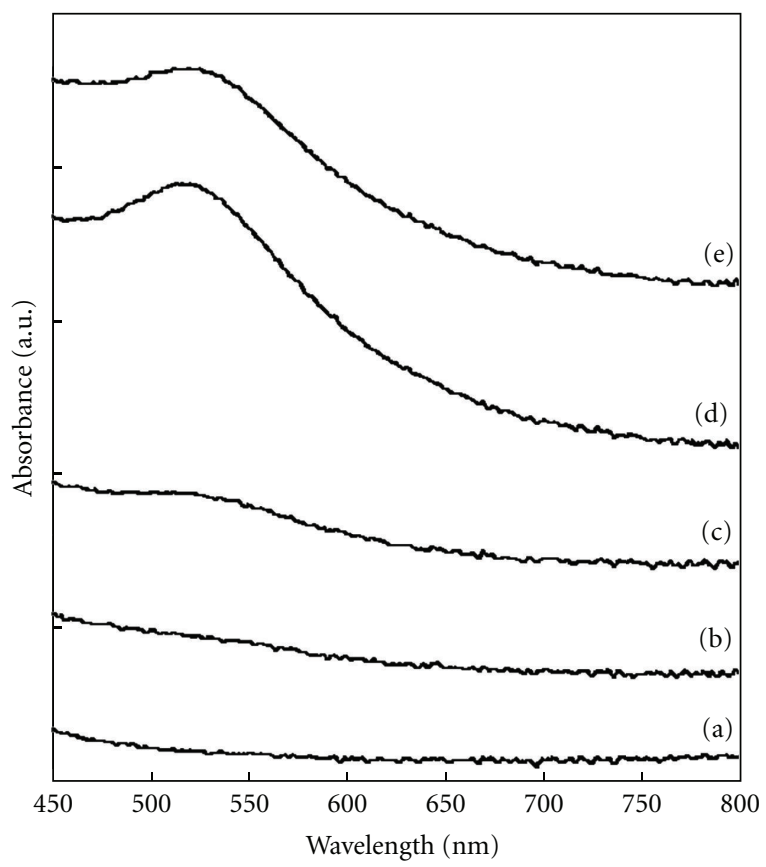

FIGURE 6: Diffuse reflectance UV-visible absorption spectra of the composite films after the calcination containing (a) 2, (b) 4, (c) 6, (d) 8 and (e) $10 \mathrm{wt} \%$ of a cross-linker to liquid PDMS.

knowledge, this article is the first report on incorporation of hydrophobic Au nanoparticles into a PDMS to lead to a simple way of fabricating Au nanoparticle-PDMS composite film.

\section{References}

[1] S. Link and M. A. El-Sayed, "Spectral properties and relaxation dynamics of surface plasmon electronic oscillations in gold and silver nanodots and nanorods," Journal of Physical Chemistry B, vol. 103, no. 40, pp. 8410-8426, 1999.

[2] U. Schürmann, W. Hartung, H. Takele, V. Zaporojtchenko, and F. Faupel, "Controlled syntheses of Ag-polytetrafluoroethylene nanocomposite thin films by co-sputtering from two magnetron sources," Nanotechnology, vol. 16, no. 8, pp. 1078-1082, 2005.

[3] Y. Kondo, Y. Kuroiwa, N. Sugimoto et al., "Third-order optical non-linearities of $\mathrm{CuCl}$-doped glasses in a near resonance region," Journal of Non-Crystalline Solids, vol. 196, pp. 90-94, 1996.

[4] B. Kutsch, O. Lyon, M. Schmitt, M. Mennig, and H. Schmidt, "Investigations of the electronic structure of nanoscaled goldcolloids in sol-gel-coatings," Journal of Non-Crystalline Solids, vol. 217, no. 2-3, pp. 143-154, 1997.

[5] A. Vaškelis, A. Jagminiene, L. Tamašauskaite-Tamašiunaite, and R. Juškenas, "Silver nanostructured catalyst for modification of dielectrics surface," Electrochimica Acta, vol. 50, no. 23, pp. 4586-4591, 2005.

[6] M. Fukushima, H. Yanagi, S. Hayashi, N. Suganuma, and Y. Taniguchi, "Fabrication of gold nanoparticles and their influence on optical properties of dye-doped sol-gel films," Thin Solid Films, vol. 438-439, pp. 39-43, 2003.

[7] R. Trbojevich, N. Pellegri, A. Frattini, O. De Sanctis, P. J. Morais, and R. M. Almeida, "Preparation and isolation of gold nanoparticles coated with a stabilizer and sol-gel compatible agent," Journal of Materials Research, vol. 17, no. 8, pp. 19731980, 2002.

[8] U. Junges, W. Jacobs, I. Voigt-Martin, B. Krutzsch, and F. Schüth, "MCM-41 as a support for small platinum particles: a catalyst for low-temperature carbon monoxide oxidation," Journal of the Chemical Society, Chemical Communications, no. 22, pp. 2283-2284, 1995.

[9] R. Leon, D. Margolese, G. Stucky, and P. M. Petroff, "Nanocrystalline Ge filaments in the pores of a mesosilicate," Physical Review B, vol. 52, no. 4, pp. R2285-R2288, 1995.

[10] A. Kumar and G. M. Whitesides, "Features of gold having micrometer to centimeter dimensions can be formed through a combination of stamping with an elastomeric stamp and an alkanethiol "ink" followed by chemical etching," Applied Physics Letters, vol. 63, no. 14, pp. 2002-2004, 1993.

[11] N. Stafie, D. F. Stamatialis, and M. Wessling, "Insight into the transport of hexane-solute systems through tailor-made composite membranes," Journal of Membrane Science, vol. 228, no. 1, pp. 103-116, 2004.

[12] S. Mandal and V. G. Pangarkar, "Separation of methanolbenzene and methanol-toluene mixtures by pervaporation: effects of thermodynamics and structural phenomenon," Journal of Membrane Science, vol. 201, no. 1-2, pp. 175-190, 2002.

[13] L. Gales, A. Mendes, and C. Costa, "Removal of acetone, ethyl acetate and ethanol vapors from air using a hollow fiber PDMS membrane module," Journal of Membrane Science, vol. 197, no. 1-2, pp. 211-222, 2002.

[14] M. A. Unger, H. P. Chou, T. Thorsen, A. Scherer, and S. R. Quake, "Monolithic microfabricated valves and pumps by multilayer soft lithography," Science, vol. 288, no. 5463, pp. 113-116, 2000.

[15] J. C. McDonald and G. M. Whitesides, "Poly(dimethylsiloxane) as a material for fabricating microfluidic devices," 
Accounts of Chemical Research, vol. 35, no. 7, pp. 491-499, 2002.

[16] M. Tagaya, M. Komura, T. Iyoda, and M. Nakagawa, "Printing of $\mathrm{Au}$ nanoparticles by Vuv-exposed patterned surfaces of a poly(dimethylsiloxane) film," Transactions of the Materials Research Society of Japan, vol. 31, pp. 273-276, 2006.

[17] D. J. Campbell, K. J. Beckman, C. E. Calderon et al., "Replication and compression of surface structures with polydimethylsiloxane elastomer," Journal of Chemical Education, vol. 76, no. 2-4, pp. 537-541, 1999.

[18] K. Efimenko, W. E. Wallace, and J. Genzer, "Surface modification of Sylgard-184 poly(dimethyl siloxane) networks by ultraviolet and ultraviolet/ozone treatment," Journal of Colloid and Interface Science, vol. 254, no. 2, pp. 306-315, 2002.

[19] Y. Tai, M. Watanabe, K. Kaneko et al., "Preparation of gold cluster/silica nanocomposite aerogel via spontaneous wet-gel formation," Advanced Materials, vol. 13, no. 21, pp. 16111614, 2001.

[20] K. V. Sarathy, G. Raina, R. T. Yadav, G. U. Kulkarni, and C. N. R. Rao, "Thiol-derivatized nanocrystalline arrays of gold, silver, and platinum," Journal of Physical Chemistry B, vol. 101, no. 48, pp. 9876-9880, 1997. 

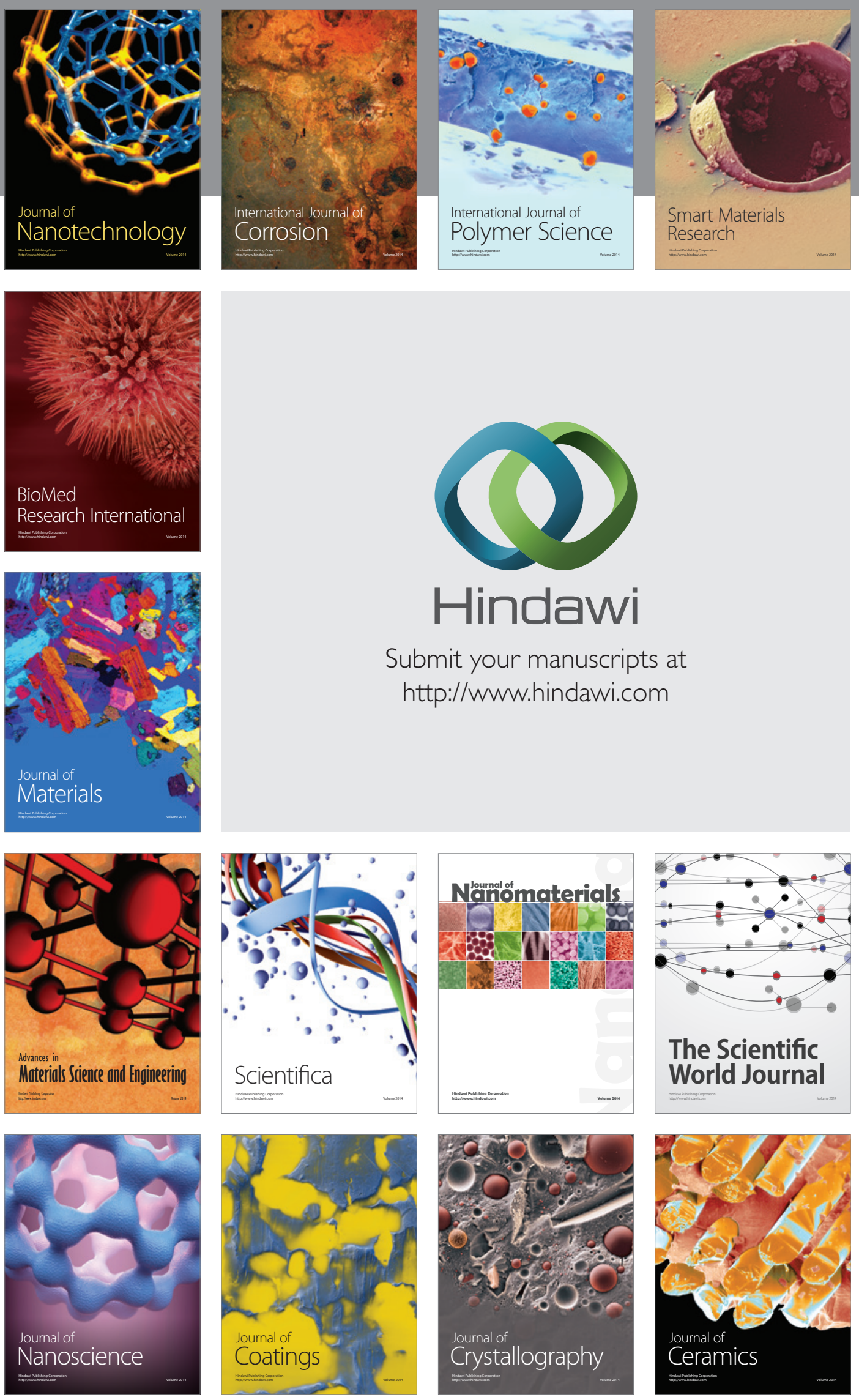

The Scientific World Journal

Submit your manuscripts at

http://www.hindawi.com

\section{World Journal}

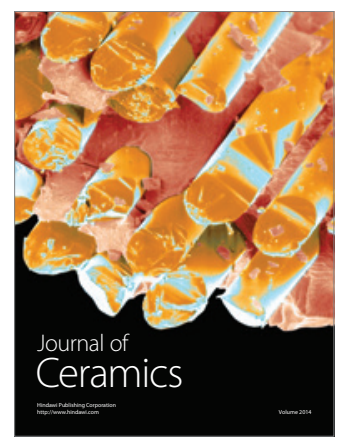

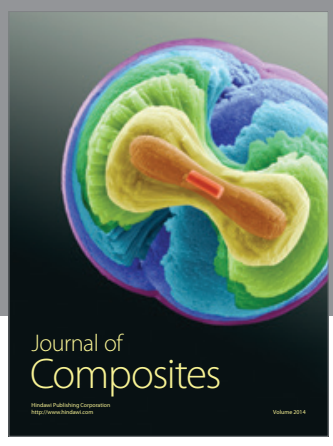
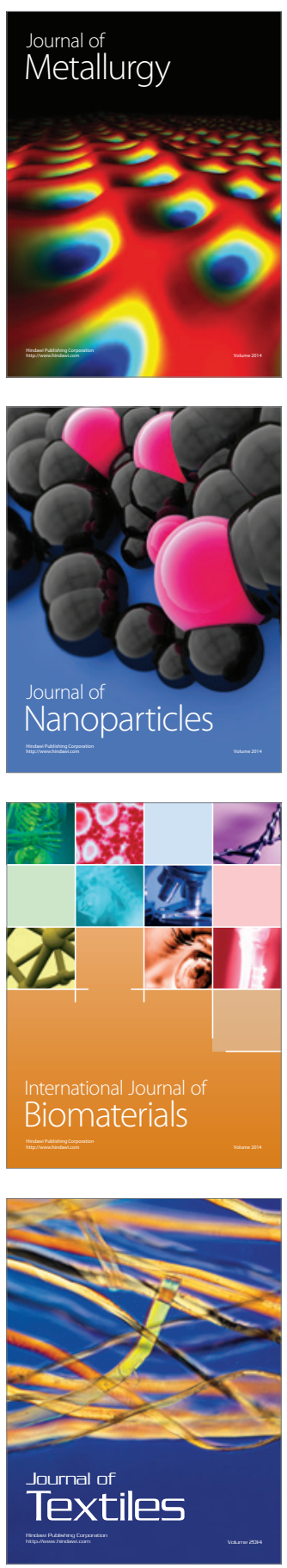